\title{
Recovery of Manganese from Ferromanganese Slag by Leaching with Sulphuric Acid
}

\author{
G.V.S. Sarma, P. Ravi Shankar Raju, K.V. Ramesh*, G.M.J. Raju \\ Department of Chemical Engineering, Andhra University, Visakhapatnam 530003, India
}

Corresponding Author Email: kvramesh69@yahoo.com

https://doi.org/10.18280/ti-ijes.650105

Received: 16 November 2020

Accepted: 11 February 2021

\section{Keywords:}

Manganese recovery, acid leaching,

ferromanganese slag

\begin{abstract}
Investigations on extraction of manganese from ferromanganese slag, a waste product from a local ferroalloy industry, were carried out using sawdust as a reducing agent. Leaching of manganese was done with sulphuric acid. The effects of particle size, stirring speed, contact time, acid concentration, temperature and dosage of reductant were studied. Based on the experimental results, the recovery of manganese increased with decreasing particle size. Optimum values of acid concentration, stirrer speed and contact time were obtained for realizing maximum recovery of manganese. With the addition of reductant, there is a significant increase in the yield of manganese.
\end{abstract}

\section{INTRODUCTION}

Manganese is an essential constituent, used in the production of steel, fertilizers, batteries, fine chemicals etc. Although primary source is sedimentary layers [1], secondary sources such as waste batteries and electrodes, steel scraps, spent catalyst, slags etc., are also equally important for recovery of manganese. In case of low grade ores, an initial pyrometallurgical processing with a succeeding hydrometallurgical processing yielded better recovery [2] Smelting, reduction-roasting, sulphatizing and chloridizing are the most effective pyrometallurgical processes. In addition, solvent extraction, electrolysis and electrowinning methods are also employed in the purification, separation and final recovery of the manganese from its sources. Many such processes are energy intense and in the present challenging days, energy efficient processes need to be developed [3].

The growing demand for manganese due to soaring global steel production in recent years causes rapid depletion of its natural resources. Hilson [4] has explained in detail the problems due to the storage and disposal of manganese wastes into the environment after their processing. In the current scenario, many researchers are concentrating on acid leaching process after reduction-roasting for better results. The present study is envisaged to recover the manganese from the ferromanganese slag collected from a local ferroalloy company through different fractions of the slag. Variables considered in the present study are presented and tabulated in the Table 1 .

Table 1.Variables used in the present study

\begin{tabular}{cccc}
\hline S.No & Parameters studied & Minimum & Maximum \\
\hline 1 & Mesh size $(\#)$ & 120 & 300 \\
2 & stirrer speed, rpm & 200 & 1200 \\
3 & contact time, min & 60 & 420 \\
4 & acid concentration, N & 0.5 & 3.5 \\
5 & Reductant weight, g & 10 & 20 \\
6 & temperature, ${ }^{\circ} \mathrm{C}$ & 30 & 90 \\
\hline
\end{tabular}

\section{MATERIALS AND METHODS}

The ferromanganese slag, procured from a local ferroalloy company was first broken into small pieces using a disintegrator then fed to a roll crusher followed by a ball mill for fine grinding. Product from ball mill was subjected to sieve analysis to separate the product into different size fractions. A representative sample was obtained by coning and quartering method. This sample was separated into six fractions through sieve analysis using six BSS mesh sieves viz., 120, 150, 170, 200,240 , and 300 .

The sample weighing exactly 1.0 grams is taken and placed in a 3-necked flat bottom flask to which sulphuric acid of chosen concentration was added. The contents of the flask were agitated at a fixed rpm and maintained at constant temperature by a magnetic stirrer cum thermocoupled temperature controller. Estimation of manganese present in the filtrate was done using Volhard's method.

\section{RESULTS AND DISCUSSION}

Preliminary experiments on trial basis to assess the manganese content were conducted with different particle sizes (fractions) of slag obtained by sieve analysis. Effect of various parameters such as size of the particle, speed of the impeller, time, acid concentration, temperature and reductant (sawdust) on the extraction of manganese from the slag have been discussed in the following subsections.

\subsection{Influence of particle size}

Figure 1 gives the data on recovery of manganese plotted against different mesh numbers. It is observed from the plot of this figure that the recovery increased with mesh size. It is known that the particle size decreases with increase in mesh size. Therefore, the total surface area of the given mass of particles increases with mesh number. Hence recovery of manganese increased with increasing mesh number. 


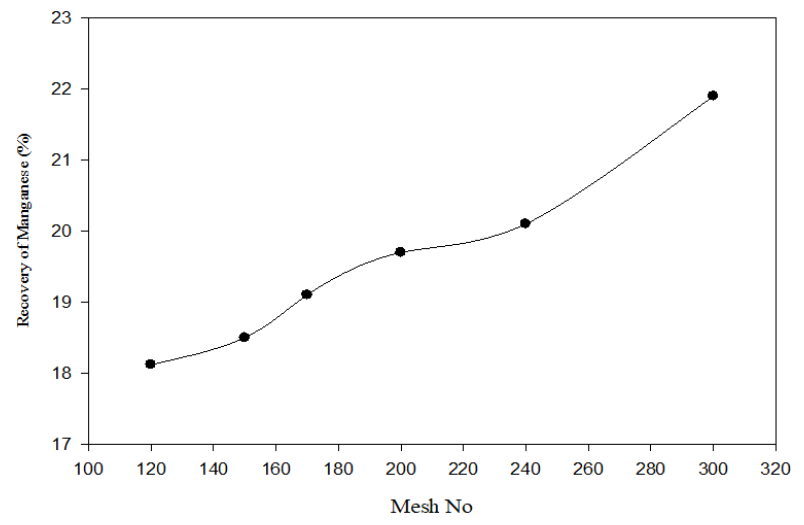

Figure 1. Effect of particlle size (Mesh no) on leaching of manganese

\subsection{Effect of acid concentration}

Data on the recovery of manganese obtained with different concentrations of acid were plotted and shown in Figure 2 for different mesh numbers. It is observed from the plots that the recovery of the manganese increased upto $2.5 \mathrm{~N}$ for all particle sizes considered. However, the manganese recovery decreased very slightly beyond an acid concentration of $2.5 \mathrm{~N}$ for all particle sizes. Thus, $2.5 \mathrm{~N}$ was taken as the optimum acid concentration for manganese leaching. Similar observations were also reported by Ghafarizadesh et al. [5].

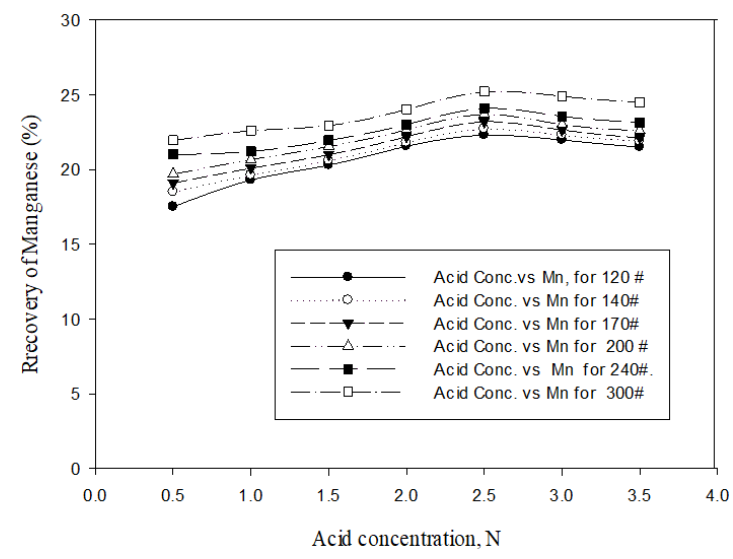

Figure 2. Effect of acid concentration on recovery of manganese

\subsection{Effect of RPM}

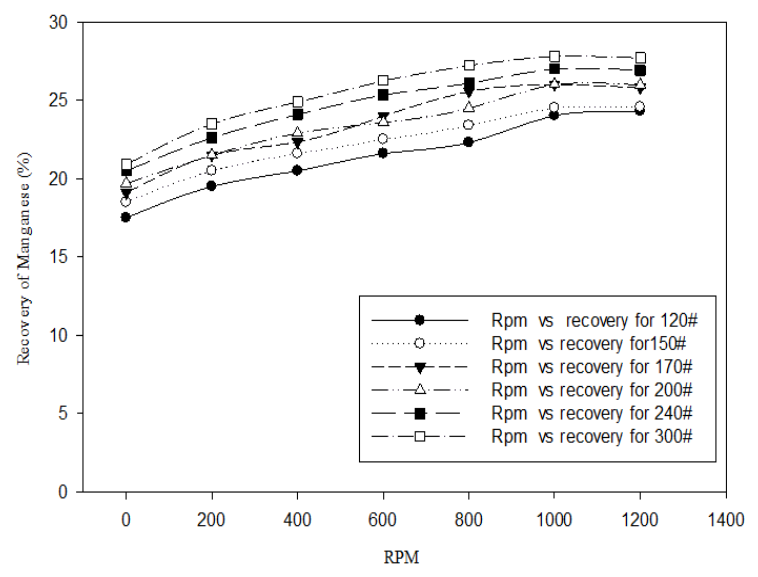

Figure 3. Effect of RPM on leaching of manganese
Figure 3 shows that the data on recovery of manganese were plotted against RPM for different particle sizes. It was observed from the plots of this figure that the recovery of manganese increased with an increase in the agitation rate. With the increase of agitation rate from 0 to $1000 \mathrm{rpm}$, the leaching of manganese augmented from $18 \%$ to $28 \%$. This is due to the result of enhancement of external mass transfer between the solid particles and liquid. Moreover, when the agitation rate exceeds $1000 \mathrm{rpm}$, the leaching of manganese became almost constant. Hence, $1000 \mathrm{rpm}$ is the optimum value. Similar observations were also reported byYoucai et al. [6].

\subsection{Effect of temperature}

The plots of Figure 4 represent the data on recovery of manganese against temperature for six different particle sizes of manganese slag. From the plots, it was observed that the recovery of manganese increased with increase in the temperature for all the particle sizes. The temperature at which maximum recovery of manganese could be obtained was strongly dependent on particle size. For finest particles of the present study, i.e., 300\#, nearly highest recovery was seen at $50^{\circ} \mathrm{C}$. Similarly for $240 \#, 60^{\circ} \mathrm{C}$ was the optimum temperature. For other sizes, the recovery was maximum at the highest temperature of the present study i.e., $90^{\circ} \mathrm{C}$.

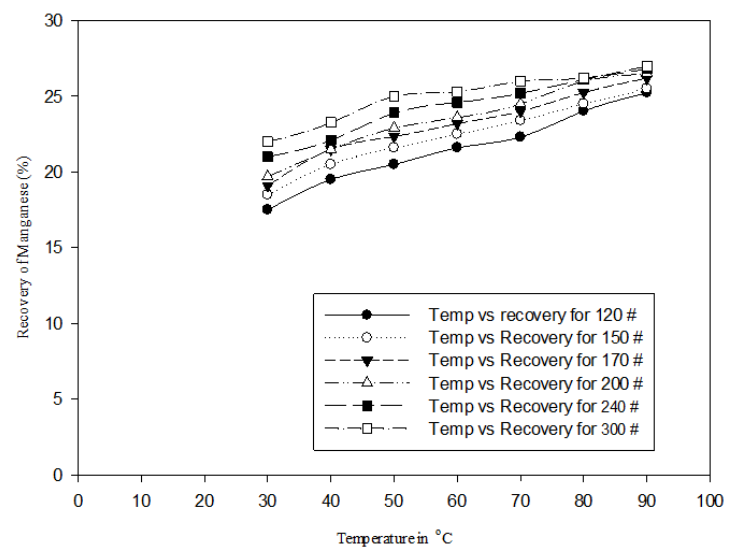

Figure 4. Effect of temperature on recovery of manganese

\subsection{Effect of contact time}

The plots of Figure 5 show the data on percent recovery of manganese drawn against contact time. Acid concentration taken was $2.5 \mathrm{~N}$ and all the six particle sizes were used at room temperature. It was noticed that there was no reckonable improvement in the recovery of manganese after $30 \mathrm{~min}$. Fine particle fractions possess higher values of recovery due to the more surface area available for participation in the reaction that tend to dissolve maximum amount of manganese.

\subsection{Effect of reductant dosage}

Sawdust, a cheaper material available in the market has been used as a reductant in this experimentation to improve the recovery values of manganese from manganese slag. Figure 6 gives the data on different dosages of sawdust as a reductant against the recovery values of manganese keeping the other parameters like particle size (150\#) and acid concentration $(2.5 \mathrm{~N})$ constant. It is observed that recovery of manganese improved tremendously when compared to the initial values of 
manganese content without reductant. This trend is due to the presence of reductant which helps to promote the dissolution of manganese. It is also noticed that an increase in the recovery of manganese is observed with respect to the increase in the dosage of reductant.

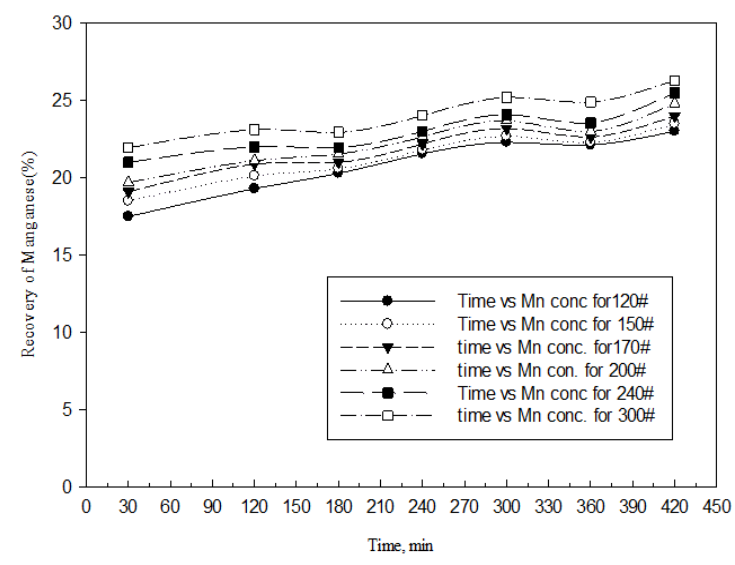

Figure 5. Effect of contact time on leaching of manganese

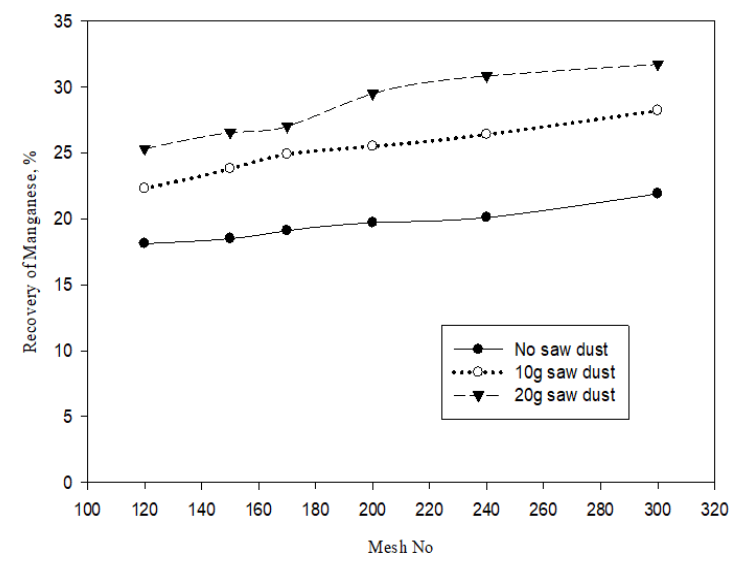

Figure 6. Effect of reductant (sawdust) on leaching of manganese

\section{CONCLUSIONS}

Experimental investigations were carried out on the manganese slag which is a waste material of local ferroalloy industry to recovery manganese through acid leaching. Based on a total of 150 runs of experiments, the following conclusions were drawn from the present study:

(i) Recovery of manganese increased with an increase in the sulfuric acid concentration upto $2.5 \mathrm{~N}$. The optimum value to get maximum recovery in the present study is $2.5 \mathrm{~N}$. (ii) As the dosage of reductant increases, recovery also increased drastically.

(iii) The recovery of manganese increased with increase in RPM values of the impeller speed. Maximum recovery was found at and RPM value of at 1000 for all the six particle sizes of the slag. Therefore, $1000 \mathrm{rpm}$ would be the optimum speed to get maximum recovery of manganese.

(iv) The yield of the recovered manganese increased with increase in the temperature.

(v) The recovery of the manganese increased with an increase in the contact time. Maximum recovery is obtained for $300 \#$ size.

\section{ACKNOWLEDGMENT}

The authors are thankful to Prof. C. Bhaskara Sarma, Retd. Professor, Department of Chemical Engineering, Andhra University, Visakhapatnam, for his encouragement to complete the present work successfully.

\section{REFERENCES}

[1] Kaneko, T., Matsuzaki, T., Kugimiya, T., Ide, K., Kumakura, M., Kasama, A. (1993). Improvement of Mn Yield in less slag blowing at BOF by use of sintered manganese ore. Testsu-To-Hagane/Journal of the Iron and Steel Institute of Japan., 79: 941-947.

[2] Kohanga, T., Imamura, M., Takahashi, J., Tanaka, N., Nishizawa, T. (1995). Recovering iron, manganese, copper, cobalt and high purity nickel from sea nodules. Journal of Minerals, 47: 40-43. https://doi.org/10.1007/BF03221339

[3] Polonara, F. (2020). The future of energy. Tecnica Italiana - Italian Journal of Engineering Science, 64: 710. https://doi.org/10.18280/ti-ijes.640102

[4] Hilson, G. (2003). Defining cleaner production and pollution prevention in the mining context. Minerals Engineering, 16 : 305-321. https://doi.org/10.1016/S0892-6875(03)00012-8

[5] Ghafarizadesh, B., Rashchi, F., Vahidi, E. (2011). Recovery of manganese from electric arc furnace dust of ferromanganese production units by reductive leaching. Minerals Engineering, 24: 174-176. https://doi.org/10.1016/j.mineng.2010.11.003

[6] Youcai, L., Qingquan, L., Lifeng, L., Jiangang, F., Zhongsi, Z., Chongqing, W., Dong, Q. (2014). Study on hydrometallurgical process and kinetics of manganese extraction from low-grade manganese carbonate ores. International Journal of Mining Science and Technology, 24: 567-571. https://doi.org/10.1016/j.ijmst.2014.05.022 